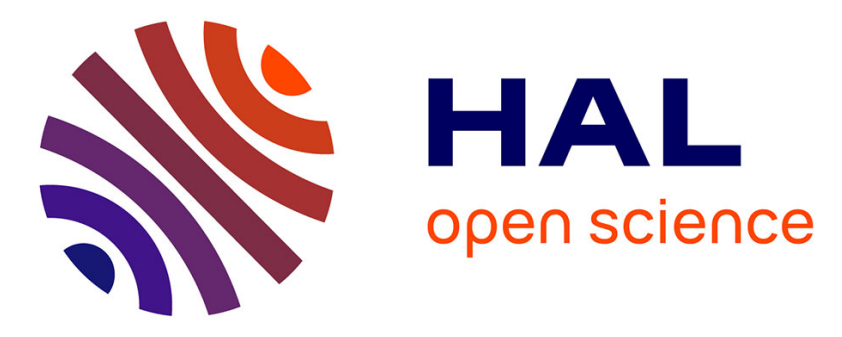

\title{
Textile split ring resonator antenna integrated by embroidery
}

\author{
Jianping Hao, A. Leblanc, Ludovic Burgnies, Amine-Rami Djouadi, Cédric \\ Cochrane, François Rault, Vladan Koncar, Eric Lheurette
}

\section{- To cite this version:}

Jianping Hao, A. Leblanc, Ludovic Burgnies, Amine-Rami Djouadi, Cédric Cochrane, et al.. Textile split ring resonator antenna integrated by embroidery. Electronics Letters, 2019, Electronics Letters, 55 (9), pp.508-510. 10.1049/el.2019.0625 . hal-02474158

\section{HAL Id: hal-02474158 https://hal.univ-lille.fr/hal-02474158}

Submitted on 11 Feb 2020

HAL is a multi-disciplinary open access archive for the deposit and dissemination of scientific research documents, whether they are published or not. The documents may come from teaching and research institutions in France or abroad, or from public or private research centers.
L'archive ouverte pluridisciplinaire HAL, est destinée au dépôt et à la diffusion de documents scientifiques de niveau recherche, publiés ou non, émanant des établissements d'enseignement et de recherche français ou étrangers, des laboratoires publics ou privés. 
This paper is a postprint of a paper submitted to and accepted for publication in Electronics Letters and is subject to Institution of Engineering and Technology Copyright. The copy of record is available at IET Digital Library.

\section{Textile split ring resonator antenna integrated by embroidery}

\author{
J. Hao, A. Leblanc, L. Burgnies, A. Djouadi, C. Cochrane, F. \\ Rault, V. Koncar and É. Lheurette
}

\begin{abstract}
A split ring resonator (SRR) antenna integrated in textile by embroidery is reported. The antenna was designed and produced by targeting two goals. First, a size reduction of the antenna was achieved by means of an SRR. Secondly, the connection loss was reduced by using a copper wire dipole fixed by embroidery. On the basis of numerical simulations, three operating modes are evidenced depending on the individual resonance frequency either of the dipole or resonator-related. Especially, a balanced mode is confirmed by experiments with two resonances measured at $1.8 \mathrm{GHz}$ and $2.2 \mathrm{GHz}$ with a return loss greater than $31 \mathrm{~dB}$. Finally, the textile antenna exhibits a radiation pattern similar to the radiation pattern of a dipole antenna.
\end{abstract}

Introduction: Using metamaterials to improve antenna performances is currently considered in literature. Metamaterials are commonly regarded for the compactness of antennas thanks to their resonant feature [1]-[5]. Especially, an electrically small antenna can be achieved by loading a radiative element (electric monopole, dipole, or patch antenna) with a resonant metamaterial operating in epsilon- or in mu- negative regime [5]. All the metamaterial cells can be involved, provided that they can be efficiently coupled to the radiative element. However, the split ring resonator (SRR), which can be magnetically coupled to an electric monopole, has widely spread for metamaterial antennas [4]-[6]. Beyond compactness, other attractive antenna behaviours can be achieved by introducing metamaterials. We can mention a bandwidth enhancement by using SRR resonators [1] or spiral resonators [2]; a gain improvement by a planar artificial magnetic conductor [7]; a reduction of sidelobe radiations by a thin metamaterial lens [8]; a reduction of the specific absorption rate (SAR) in multi-standard mobile bands by a metamaterial loaded ground plane [9]; and a multi-band operation of an SRR coupled monopole antenna [6]. The miniaturised antennas were generally developed in printed circuit board (PCB) technology which seems not suitable for body-worn applications such as wireless body area networks. Therefore a textile integration of antennas was sought [10]-[12] and textile materials for electromagnetic applications were designed by several groups [13], [14]. Finally, the connection of electronics in smart textiles is still a challenge and realistic solutions have to be found.

In this Letter, an S-shaped SRR resonator antenna produced by embroidery is proposed. On one hand, connection loss was limited by choosing a radiative element made of copper which can be easily soldered and fixed on the textile by dielectric yarn embroidery. On the other hand, size reduction was produced by embroidering SRR resonator patterns with conductive yarn.

Design of the antenna: The antenna shown in Fig. 1 is composed of an Sshaped dipole defined by the diameter $D$ and two SRRs, each of them defined by $d_{1}$ and $d_{2}$. The circular shape has been chosen in order to make easier the manufacture of resonators by embroidery and to limit conduction loss. Such a loss dramatically increases for an embroidered square resonator due to the change of metallic yarn direction on the corner. Then, the S-shape of the dipole makes possible to increase first the coupling with SRRs and also to decrease the resonance frequency in comparison with a straight dipole of length $2 D$. In the industrial scientific and medical (ISM) band $2.4 \mathrm{GHz}$, the resonance frequency of the dipole can shift of $1 \mathrm{GHz}$ by using an S-shape. The operation of the antenna is based on the resonance of the SRRs. By increasing the capacitance between concentric rings, the resonance frequency of an SRR can be reduced yielding a size reduction of the antenna. Fig. 2 shows the reflection coefficient of the antenna with the gap between concentric split rings as a parameter. The simulation was performed with the software HFSS from Ansys for a dipole diameter $D=21 \mathrm{~mm}$ and a diameter of the outer ring $d_{2}=16 \mathrm{~mm}$. Then, the inner ring diameter $d_{l}$ was varied producing a gap between rings of $0.25,0.75$, and $1.5 \mathrm{~mm}$. The other simulation parameters were set from a preliminary fabrication study: a $1 \mathrm{~mm}$-strip width of SRRs, a $0.2 \mathrm{~mm}$-dipole width and a $0.2 \mathrm{~mm}$-slot for each ring. Conductivity for SRRs was $\sigma=1.410^{5} \mathrm{~S} / \mathrm{m}$.

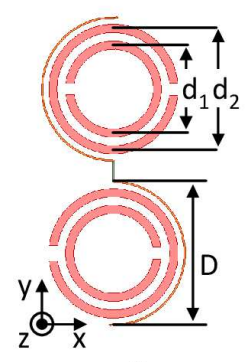

$a$

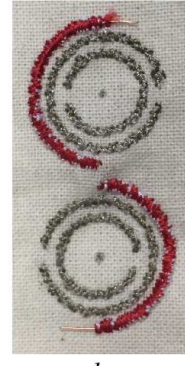

$b$

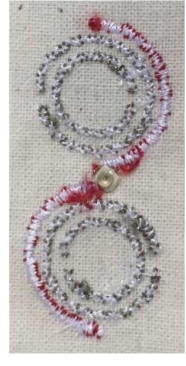

$c$
Fig. 1 Illustration of the SRR antenna.

$a$ Schematic view with parameters definition.

$b$ Embroidered antenna, front view.

$c$ Embroidered antenna, back view with UFL connector.

In Fig. 2, three different operating modes can be noted. For a gap of $0.25 \mathrm{~mm}$, the reflection dip observed at $1.45 \mathrm{GHz}$ is associated with the split rings resonance whereas the second resonance corresponds to the dipole. When the gap increases the resonance frequency of the SRRs increases as a consequence of the decrease of the capacitance between concentric rings. For a gap of $0.75 \mathrm{~mm}$ the resonance of the SRRs and of the dipole are near each other and it is difficult to associate each of the dip to a specific resonance. Then, for a gap greater than $0.75 \mathrm{~mm}$ the resonance frequency of the SRRs becomes higher than the dipole resonance. Depending on the objective, the gap between rings can be adjusted in order to achieve a size reduction of the antenna for a small gap between rings, or a double band operation with two close resonances. However for the gap of $0.25 \mathrm{~mm}$, the return loss at the SRR resonance is lower than $5 \mathrm{~dB}$ resulting from a bad impedance matching of the antenna. This is a consequence of the conductivity of the embroidered yarn which is more than three orders of magnitudes lower than the conductivity of the copper in PCB technology. Alternatively, the balanced mode $(0.75 \mathrm{~mm})$ shows two good impedance matching conditions at resonances with a return loss higher than $15 \mathrm{~dB}$. Consecutively, we focused our work on this balanced operating mode aiming at producing an SRR antenna with double band operation.

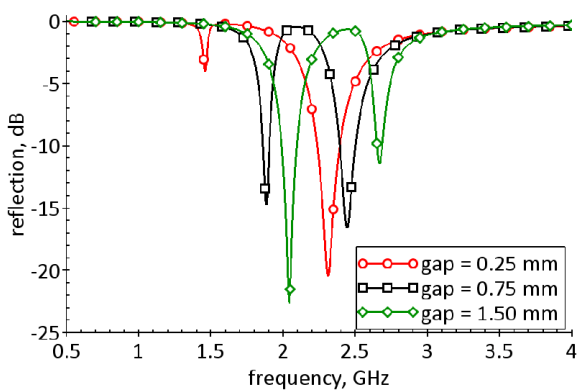

Fig. 2 Reflection coefficient with the gap between concentric rings as a parameter.

Fabrication: For embroidery of the SRRs, a silver-based conductive yarn (Shieldex ${ }^{\circledR}$ Twisted Yarns 117/17 dtex 2-Ply from Statex) was used for upper threading whereas a polyester dielectric yarn was used for lower threading. The conductive yarn consists of metallic multifilament and hairiness due to the filament breakage during embroidery appears. Such hairiness might short-circuit concentric rings and remove the resonance as a consequence. Therefore, embroidery for the resonators fabrication was first studied in order to define the minimum value of the gap between concentric rings which can be reached without any risk of an electric contact between the rings. It was concluded to fix the gap at $1 \mathrm{~mm}$. Then, the S-shaped dipole was produced by a copper wire of diameter $0.2 \mathrm{~mm}$ fixed onto the textile by embroidering polyester yarns. At last, an UFL connector was soldered in the middle of the dipole and on the back side for measurements. Front and back views of the fabricated SRR antenna are shown in Fig. 1. As the SRR antenna is connected by means of a 
copper dipole, it is expected that the connection loss will be low, thus answering the common connection issue of smart textiles. Finally, we can note that each end of the dipole can be cut after fabrication. It is then possible to easily adjust the resonances of the SRR antenna by changing the length of copper wires.

Characterisation: The antenna was characterised by means of a vector network analyser previously calibrated in the plane of the UFL connector (SOLT calibration). Such a calibration allows analysing the input impedance of the SRR antenna calculated from the measured reflection coefficient. The measured reflection coefficient is plotted in Fig. 3. The antenna operates in balanced mode with two resonances at 1.8 and $2.2 \mathrm{GHz}$. At resonances, the return loss is higher than $33 \mathrm{~dB}$ reflecting a good impedance matching.

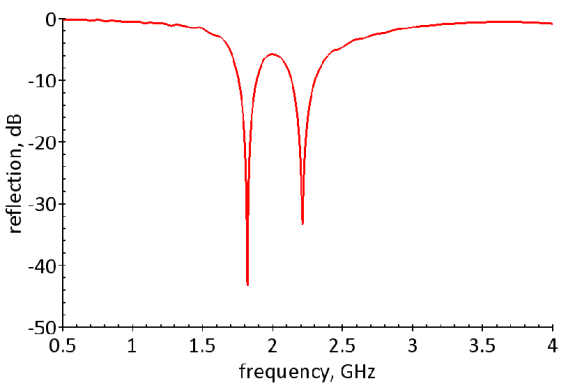

Fig. 3 Measured reflection coefficient of the SRR antenna.

In order to validate the balanced operating mode, the input admittance of the antenna calculated from the measured reflection coefficient is shown in Fig. 4. Two series resonances are evidenced with good impedance matching corresponding to a maximum value of the admittance of $20 \mathrm{mS}$. Admittance looks like two coupled resonators with close resonances. The small capacitive behaviour of the admittance at $1.8 \mathrm{GHz}$ suggests that the SRRs are concerned with the lower resonance frequency whereas the imaginary part is zero at the dipole resonance.

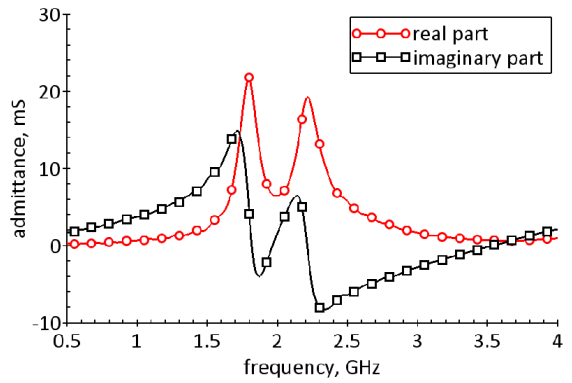

Fig. 4 Input admittance of the SRR antenna.

The radiation pattern shown in Fig. 5 and the gain of the antenna were measured in an anechoic chamber at each of the resonance frequency. The radiation pattern is similar to the radiation pattern of a dipole antenna (without SRR) because the dipole is the radiative element. At last, the measured gain was $0 \mathrm{dBi}$ and $-3.1 \mathrm{dBi}$ at 1.8 and $2.2 \mathrm{GHz}$, respectively.

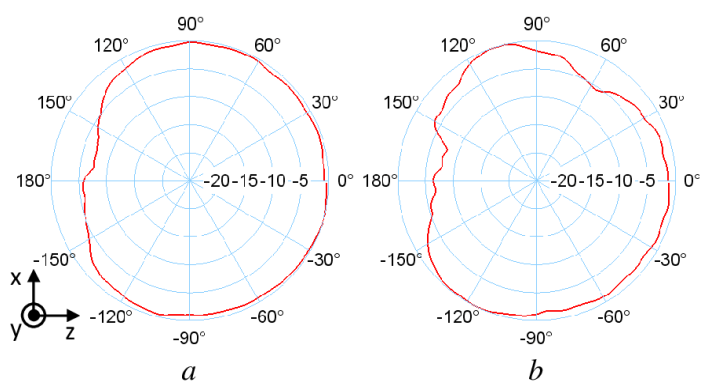

Fig. 5 Radiation pattern.

a Measured at $f=1.8 \mathrm{GHz}$.

$b$ Measured at $f=2.2 \mathrm{GHz}$.

Conclusion: A full textile antenna made of SRRs coupled to an S-shaped dipole has been designed, manufactured, and characterised. The antenna was designed for a double band operation thanks to a balanced mode between resonances of SRRs and of the dipole. SRRs were fabricated by metallic yarn embroidery whereas a copper wire was used for the dipole in order to lower connection loss. Experimental results validate a double band operation with a radiation pattern similar to the radiation pattern of a dipole.

Acknowledgments: This work was supported financially by the Fonds Européen de Développement Régional/ Met steun van het Europees Fonds voor Regionale Ontwikkeling in the framework of the European Interreg V France-Wallonie-Vlaanderen project named Luminoptex.

J. Hao, L. Burgnies, A.-R. Djouadi, and É. Lheurette (Univ. Lille, CNRS, Centrale Lille, ISEN, Univ. Polytech. H-d-F, UMR 8520 - IEMN, F-59000 Lille, France)

E-mail: ludovic.burgnies@iemn.univ-lille1.fr

A. Leblanc, C. Cochrane, F. Rault, and V. Koncar (ENSAIT, GEMTEX Laboratoire de Génie et Matériaux Textiles, F-59000 Lille, France)

L. Burgnies: Also with Université du Littoral Côte d'Opale, Calais, France

\section{References}

1 Islam, M. M., Islam, M. T., Samsuzzaman, M., Faruque, M. R. I., "Compact metamaterial antenna for UWB applications," Electron. Lett., 2015, 51, (16), pp. 1222-1224, doi:10.1049/el.2015.2131.

2 Aeini, M., Jarchi, S., Faraji-Dana, R., "Compact, wideband-printed quasi-Yagi antenna using spiral metamaterial resonators," Electron. Lett., 2017, 53, (21), pp. 1393-1394, doi:10.1049/el.2017.2149.

3 Pandey, G. K., Singh, H. S., Bharti, P. K., Meshram, M. K., "Metamaterial-based UWB antenna," Electron. Lett., 2014, 50, (18), pp. 1266-1268, doi:10.1049/el.2014.2366.

4 Alici, K. B., Ozbay, E., "Electrically small split ring resonator antennas," J. Appl. Phys., 2007, 101, (8), p. 083104, doi:10.1063/1.2722232.

5 Dong, Y., Itoh, T., "Metamaterial-Based Antennas," Proceedings of the IEEE, 2012, 100, (7), pp. 2271-2285, doi:10.1109/JPROC.2012.2187631.

6 Ntaikos, D. K., Bourgis, N. K., Yioultsis, T. V., "Metamaterial-Based Electrically Small Multiband Planar Monopole Antennas," IEEE Antennas Wirel. Propag. Lett., 2011, 10, pp. 963-966, doi:10.1109/LAWP.2011.2167309.

7 Su, R., Gao, P., Wang, R., Wang, P., "High-gain broadside dipole planar AMC antenna for $60 \mathrm{GHz}$ applications," Electron. Lett., 2018, 54, (7), pp. 407-408, doi:10.1049/el.2017.2519.

8 Chen, X., Ge, Y., Bird, T. S., "Reduction of sidelobe radiations of the standard pyramidal horn using a thin metamaterial lens," Electron. Lett., 2016, 52, (24), pp. 1973-1974, doi:10.1049/el.2016.3336.

9 Alam, T., Faruque, M. R. I., Islam, M. T., "Specific absorption rate reduction of multi-standard mobile antenna with double-negative metamaterial," Electron. Lett., 2015, 51, (13), pp. 970-971, doi:10.1049/el.2015.1141.

10 Kamardin, K., Rahim, M. K. A., Hall, P. S., Samsuri, N. A., "Vertical and horizontal transmission enhancement between antennas using textile artificial magnetic conductor waveguide sheet," Electron. Lett., 2015, 51, (9), pp. 671-673, doi:10.1049/el.2014.3955.

11 Tronquo, A., Rogier, H., Hertleer, C., Langenhove, L. V., "Robust planar textile antenna for wireless body LANs operating in $2.45 \mathrm{GHz}$ ISM band," Electron. Lett., 2006, 42, (3), pp. 142-143, doi:10.1049/el:20064200.

12 Yan, S., Soh, P. J., Vandenbosch, G. A. E., "Wearable dual-band composite right/ left-handed waveguide textile antenna for WLAN applications," Electron. Lett., 2014, 50, (6), pp. 424-426, doi:10.1049/el.2013.3529.

13 Burgnies, L., Huppé, C., Ducournau, G., Cochrane, C., Rault, F., Koncar, V., Lheurette, É., "High-Pass Sub-mmWave Filtering by Woven Textile Metamaterials," IEEE Trans. Terahertz Sci. Technol., 2018, 8, (4), pp. 427-433, doi:10.1109/TTHZ.2018.2844096.

14 Tennant, A., Hurley, W., Dias, T., "Knitted, textile, high impedance surface with integrated conducting vias," Electron. Lett., 2013, 49, (1), pp. 8-10, doi:10.1049/el.2012.3896. 